\title{
Discussion on "Some Features Affecting the Parallel Operation of Synchronous Motor-Generator Sets," at New York, March 23, 1906.
}

W. L. Waters: In the operating of synchronous motorgenerators, my own experience has, unfortunately, not shown quite such simple results as those indicated by Mr. Taylor. One installation of synchronous motor-generators will work very well, the machines will divide their load properly, and the load can be changed from one machine to another by means of the field rheostat; while another installation which is apparently very similar will give considerable trouble, even after the machines are lined up and the connections correctly made. Suppose a 500-kw. machine is running on full load and a second machine is thrown in, then this second machine might take $40 \%$ of the load or it might take $60 \%$; and as further load comes on the machines, it may be divided proportionately between them, or it may not. The results obtained from the machines seem to be different every time the machines are thrown together. The reason for this is not particularly clear, but it, has been suggested that the explanation is to be found in the different condition of the outside circuit and of the load at the time. Most of these machines carry a load which is by no means balanced. The distribution system being three singlephase circuits rather than three phase. The result of this is that there may be very bad conditions of unbalancing, both of load and power-factor, between the different phases, and that these conditions may vary widely from time to time.

Referring to Mr. Taylor's vector diagrams, it will be noticed that he considers that the effect of the internal reactions in an alternator can be represented by a single vector whose magnitude is proportional to the current in the armature, and independent of the phase of that current. Referring specifically to Figs. 3 and 4 , this means that the vector "inductive and demagnetizing drop " is constant in magnitude, and independent of the power-factor of the load. This is a pure assumption, and this assumption may possibly explain some of the peculiar results mentioned above. Mr. Taylor's assumption is equivalent to the statement that if there are two alternators for which the angle $(\beta)$ is the same on unity powerfactor, then it will be the same for these two machines on all power-factors, This, I think, is by no means always the case. Assuming, then, that this is not necessarily true, we have at once an explanation of the apparently contradictory experimental results mentioned above. And we can say that though two synchronous motor-generators may divide their load perfectly on a balanced load of unity power-factor, it does not necessarily follow that they will distribute their load so well when that load is unbalanced and of a lower power-factor.

Mr. Taylor points out the important fact that when two 
synchronous motor-generators are thrown together, they are not strictly in phase; by the synchronoscope, the incoming machine is shown to be leading. The station operator often thinks that this difference in phase results from the machines not being correctly set up, and that this is the cause of some of the peculiar results obtained. The way to find out whether the machines are set up and connected correctly is to parallel them on no load; in that case, with correct motor excitation, there should be no difference in phase.

Referring to the starting of these machines, I think the old method of reversing the field of the motor is unnecessarily severe on the machines. Though modern machines will stand this without damage it is always poor practice to put any unnecessary strain on any machine. I think Mr. Taylor's method of using a synchronoscope with two pointers is much superior.

I think that the subject of synchronous motor-generator sets is still one in which practical results are more valuable than theoretical explanations, and this paper, though perhaps not exhaustive, will certainly give something standard to work from in the future.

J. B. Taylor: Mr. Waters objects to the use of a reversingfield switch in connection with a synchronous motor. I think a little consideration will show that this objection is not valid. Every synchronous motor must go through this process of "slipping" at times; that is to say, it locks in synchronism, and when the field is excited there is one chance in two that the motor will slip a pole.

Furthermore, in the practical operation of a synchronous motor-generator set the slipping is done while the set is connected to the starting taps, so that the increase in current and strain on the machine is not great. Since every synchronous motor must slip at times, and this method of phasing means that the motor may have to slip two or three times in succession, it will not hurt the motor, as it must be constructed so that it will stand the work year in and year out. 